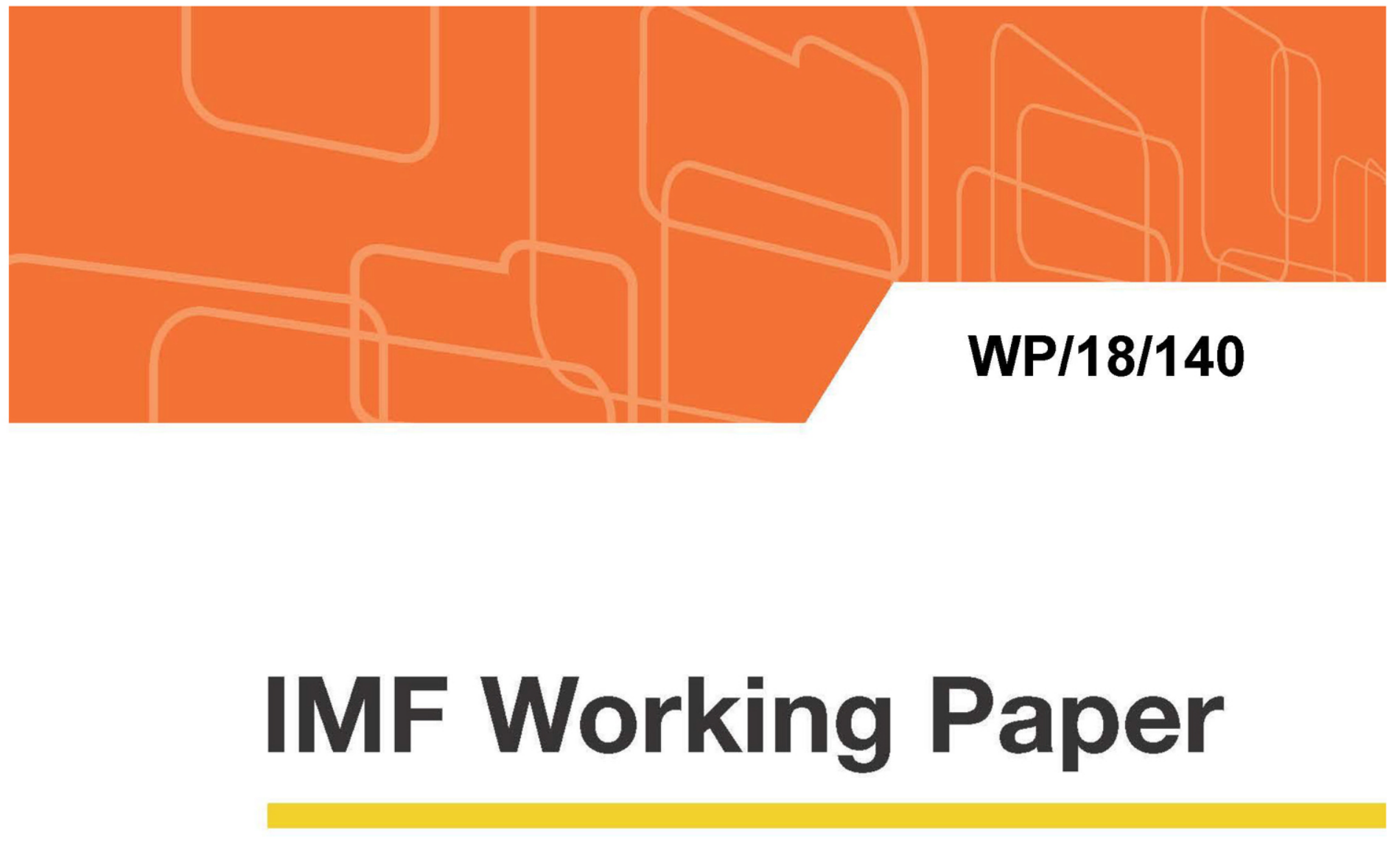

\title{
A Macroeconomic Approach to the Term Premium
}

\author{
by Emanuel Kopp and Peter D. Williams
}

IMF Working Papers describe research in progress by the author(s) and are published to elicit comments and to encourage debate. The views expressed in IMF Working Papers are those of the author(s) and do not necessarily represent the views of the IMF, its Executive Board, or IMF management. 


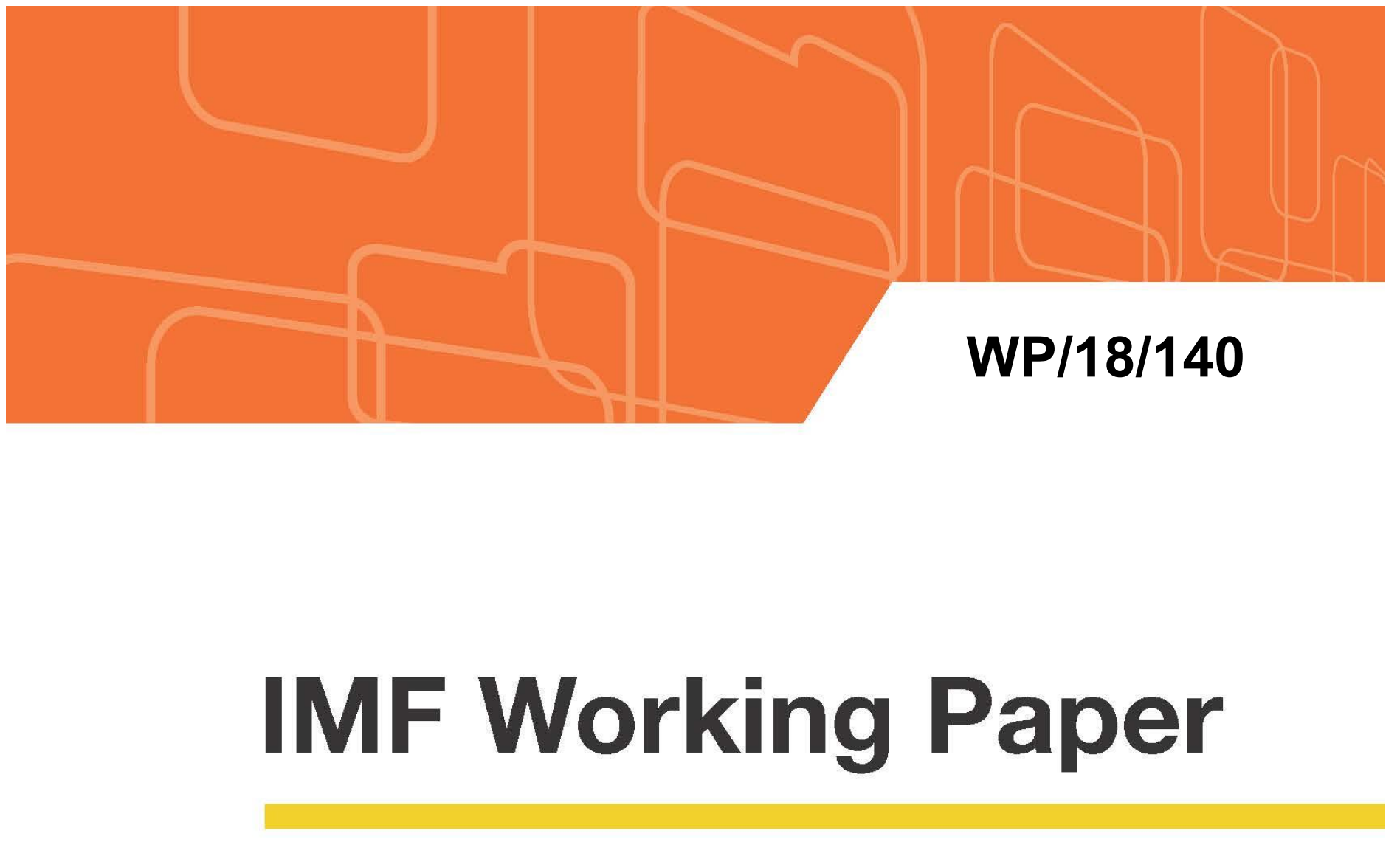

\section{A Macroeconomic Approach to the Term Premium}

by Emanuel Kopp and Peter D. Williams

IMF Working Papers describe research in progress by the author(s) and are published to elicit comments and to encourage debate. The views expressed in IMF Working Papers are those of the author(s) and do not necessarily represent the views of the IMF, its Executive Board, or IMF management.

I N T E R N A T I O N A L M O N E T A R Y F U N D 


\title{
IMF Working Paper
}

Western Hemisphere Department

\section{A Macroeconomic Approach to the Term Premium}

Prepared by Emanuel Kopp and Peter D. Williams

Authorized for distribution by Nigel Chalk

June 2018

\section{IMF Working Papers describe research in progress by the author(s) and are published to elicit comments and to encourage debate. The views expressed in IMF Working Papers are those of the author(s) and do not necessarily represent the views of the IMF, its Executive Board, or IMF management.}

\begin{abstract}
In recent years, term premia have been very low and sometimes even negative. Now, with the United States economy growing above potential, inflationary pressures are on the rise. Term premia are very sensitive to the expected future path of growth, inflation, and monetary policy, and an inflation surprise could require monetary policy to tighten faster than anticipated, inducing to a sudden decompression of term and other risk premia, thus tightening financial conditions. This paper proposes a semi-structural dynamic term structure model augmented with macroeconomic factors to include cyclical dynamics with a focus on medium- to long-run forecasts. Our results clearly show that a macroeconomic approach is warranted: While term premium estimates are in line with those from other studies, we provide (i) plausible, stable estimates of expected long-term interest rates and (ii) forecasts of short- and long-term interest rates as well as cyclical macroeconomic variables that are stunningly close to those generated from large-scale macroeconomic models.

JEL Classification Numbers: D5, D62, D82, G2, H41.

Keywords: term structure of interest rates, term premium, yield curve, State Space.

Author's E-Mail Address: ekopp@,imf.org, pwilliams2@,imf.org .
\end{abstract}


II. MODELING THE TERM STRUCTURE OF INTEREST RATES___

A. Data and Variables ___ _ _ 1

B. Model Specification___ 10

III. MACROECONOMIC IMPLICATIONS____ 17

IV. CONCLUSION ___

REFERENCES _ _

FIGURES

1. Term Structure of Interest Rates ___ 4

2. Term Premium Estimates___ $\underline{5}$

3. Unit Roots and Mean-Reverting Variables ___ 10

4. Macroeconomic Outputs___ 12

5. Trends in Interest Rates ___ 14

6. Cyclical components of interest rates___ 14

7. Comparison of 10-year Term Premium Estimates___ 16

8. Average Term Premia ____ 16

9. Survey-based Long Horizon Interest Rate Forecasts ___ 17

10. Expected Risk-Free Rates in the Longer-Term ___ 18

11. Survey-Based Long Horizon Interest Rate Forecasts___ 19

\section{TABLES}

1: Destriptive Statistics of the Input Data____

2. Correlation between Yield Curve Factors and Macroeconomic Variables____ $\underline{9}$ 


\section{INTRODUCTION}

With growth in the United States projected to accelerate above full employment, and monetary policy expected to tighten further, the behavior of the term premium has regained attention. The term premium is the compensation investors require for holding a long-term bond compared to rolling over a series of short-term bonds with lower maturity. In that sense, interest rates are driven by investors' expected average level of the risk-free rate and a compensation for the longer holding period (i.e., the term premium). Policymakers can infer information from the term structure of interest rates (Figure 1) to learn about the market's expectation of future monetary policy and to test the effectiveness of central bank communication, including forward guidance. Investors use term structure information to price, as precisely as possible, future returns on money market instruments and Treasuries, exploiting variation in the cross-section of sovereign yields.

\section{Figure 1. Term Structure of Interest Rates ${ }^{1}$}

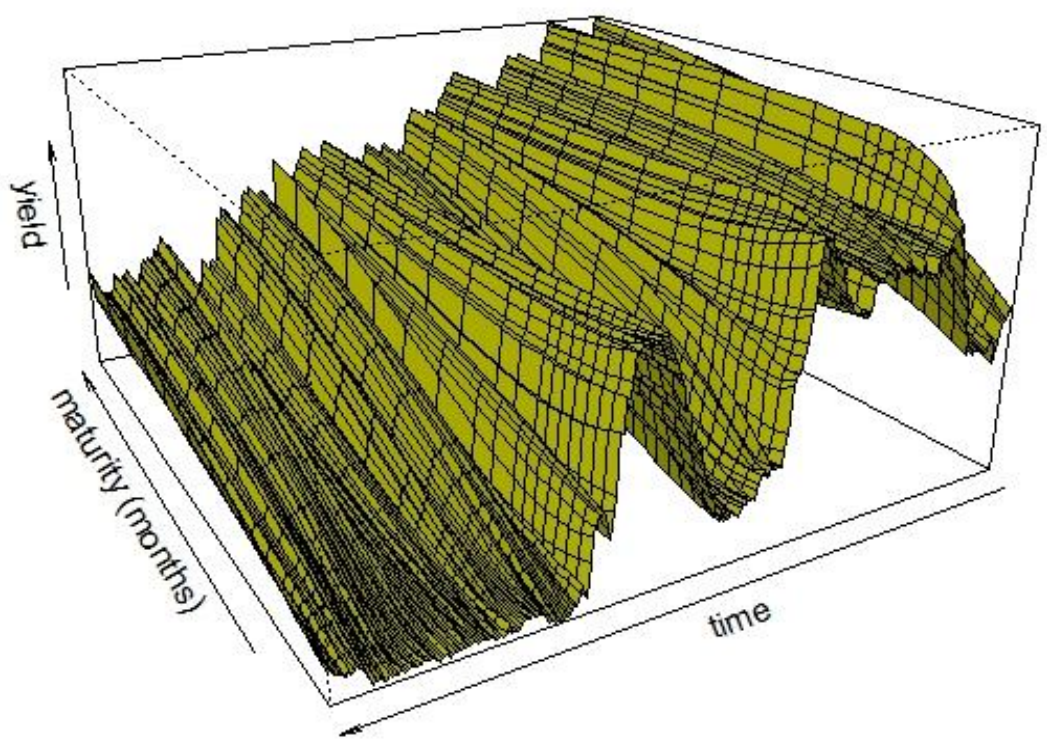

Over the last few years, the term premium has been relatively small or even negative. While the current rate hike cycle has been boosting interest rates on the short end, the higher shortterm rates have not caused long-term rates to lift, and the term premium stayed close to historical lows. At the same time, inflation expectations in the United States remained very well anchored, and resisted drifting upwards despite rising inflationary pressures, accelerating growth, and improving longer-term growth expectations. With further monetary tightening on the horizon, there is the real risk that the spread between short- and long-term rates compresses further, and that the yield curve inverts - a reliable indicator of recessions in the United States. Also, some have argued that if term premia were too low (artificially compressed, for instance), various types of shocks could induce a sudden decompression

\footnotetext{
${ }^{1}$ Illustrates interest rates with maturities of $3,6,9,12,15,18,21,24,30,36,48,60,72,84,96,108$, and 120 months from Gurkynak, Sack, and Wright (2006). Authors' illustration.
} 
which would acerbate its impact on financial markets and cause a wave of repricing of financial assets (see, for instance, GSFR, 2018).

The analysis of term premia is not straightforward as both the expected future short-term interest rate and the term premium are not directly observable or measurable. Deriving the term premium from the term structure requires making certain assumptions. Early approaches to term structure modeling rested (solely) on the Expectations Hypothesis, which says that the yield on a longer-maturity bond is equal to the average value of the risk-free rate. Over the life of the bond, the returns from these two assets should be the same. Following this hypothesis, the forward curve is the market's unbiased expectation of the risk-free rate going forward. Fama and Bliss (1987) and Campbell and Shiller (1991), among others, found little empirical support for the Expectations Hypothesis; and it has become widespread practice to decompose yields into (i) investors' expectations about the path of future short-term interest rates and (ii) a time-varying term premium.

Since both components are unobservable, a plethora of approaches has been applied to decompose movements in bond yields, which resulted in a wide range of term premium estimates. Figure 2 gives 10 -year term premium estimates resulting from the Kim and Wright (2006), a semi-structural model, and Adrian and others (2013) models, a purely statistical model. Both term premium time series show a long-term downward trend, suggesting that the term premium has become smaller over the past 25 years. While there is evidence that the narrowing term spread between long and short-term yields is associated with a decline in economic activity and inflation, it remains unclear why term spreads have this predictive power. Furthermore, term premia estimates differ substantially between the two approaches, especially in the aftermath of recessions. In fact, one of the approaches gives a negative term premium during 2011-2014, while the other approach suggests a positive risk premium (of up to 175 basis points). Considering the relatively low level of interest rates, this is a significant difference and illustrates how widely term premium estimates vary.

Figure 2. Term Premium Estimates

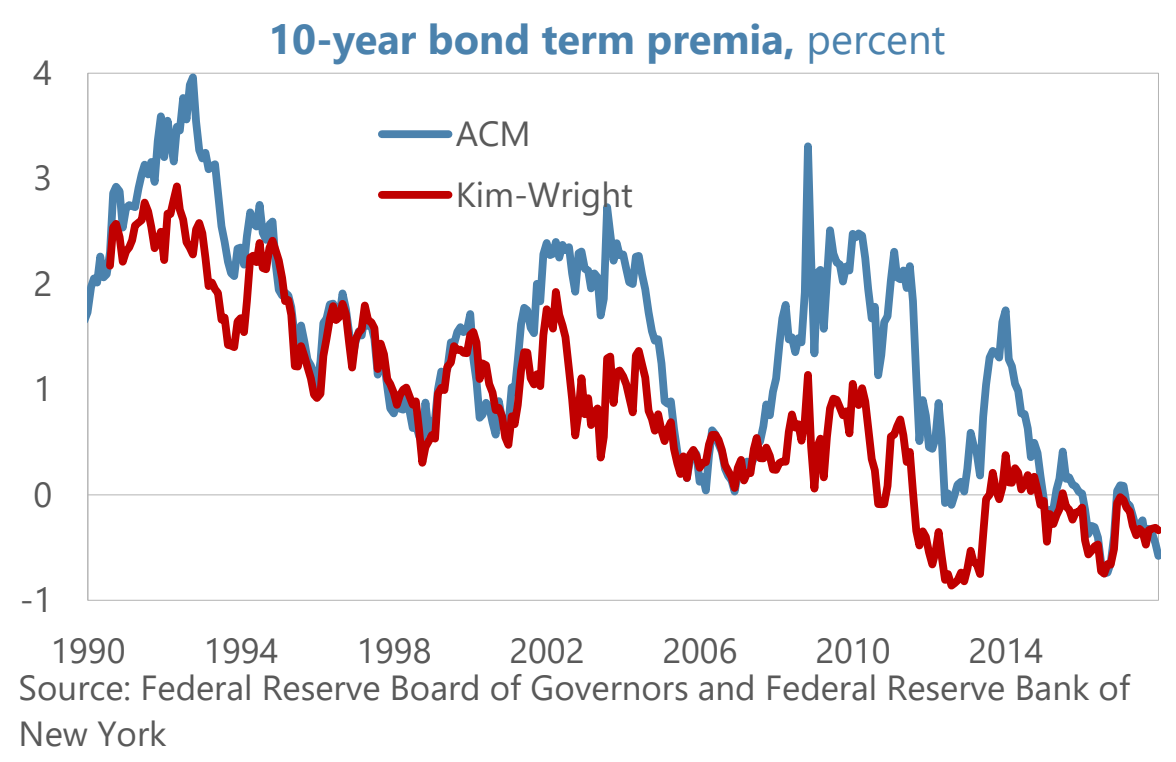


The term premium is a key concept in monetary policy. Greenwood and others (2015) argue that the optimal maturity structure of government debt should be a function of varying term premia, and find the expected path of short-term rates is the main monetary policy channel affecting longer-term yields (see, for instance, Bernanke, 2005). Others instead suggested that monetary policy can control longer-term yields only through influencing term premiums (see Crump and others, 2018). In any case, the lion's share of existing structural macroeconomic models assume that the Expectations Hypothesis holds and, hence, ignore the time variation of long-term bond yields.

In the finance literature, term structure models are mainly used to describe the joint evolution of different yields, with a focus on cross-sectional relationships. Finance models often assume a no-arbitrage property, where securities with the same risk characteristics need to have the same price. This assumption constrains the comovement of yields for bonds with different maturities, which simplifies both the modeling of the yield curve and the estimation of parameters. These so-called affine Gaussian term structure models assume that yields depend linearly on the risk factors (hence, affine), and Gaussian refers to the distributional assumption for the risk factors. Typically, the risk factors which drive these models are assumed to be stationary. However, if the underlying bond yields are trending and not stationary this assumption could bias the dynamics and intra-factor relationships of the model, possibly leading to less accurate forecasts and term premia estimates. Separately, most finance papers rely exclusively on yields as input data (for instance, Dai and Singleton 2000, Duffee 2002, Cochrane and Piazzesi 2005, Adrian and others 2013) but increasingly add macroeconomic variables to the modeling framework, including Ang and Piazzesi (2003), Crump and others (2018), Gurkynak and Wright (2012), and Wright (2011).

The body of literature on estimating future short term interest rates using expectations data is growing. The use of surveys to anchor the model's dynamics can help alleviate some of the small sample and overfitting biases that can affect these models which are rich in cross sectional variation but have a relatively small number of business cycles to estimate the intertemporal dynamics. Kim and Wright (2005) and Piazzesi and others (2015) fit jointly government bond yields and survey forecasts of short rates in affine term structure models. Crump and others (2018) propose a parametric model of the "term structure of expectations" using surveys of professional forecasters for real GDP growth, the short-term rate, and inflation. This approach suggests that term premia - rather than expected future short-term yields - are the main driver of cross-sectional variation in yields.

The term structure model presented in this paper exploits both the cross-sectional and temporal information embedded in the term structure of interest rates, and adds macroeconomic factors to a vector autoregressive model that is constrained to introduce cyclical dynamics with a focus on medium- to long-run forecasts. Expectations about structural factors like inflation or potential growth are revised only slowly, even after large shocks, pointing to high and persistent inertia in their reassessment. For instance, the Survey of Professional Forecasters suggests that it has taken economists several years following the crisis to adapt their views on what the average level of interest rates should be. A similar pattern is apparent in the Federal Reserve's Summary of Economic Projections and the CBO's long-run forecasts of potential growth. We show that the structure of the model 
presented in this paper allows for more stable and realistic forecasts of risk-free rates which are the basis for estimating the term premium (hence, it is a macroeconomic approach to the term premium). Also, estimates of the level of the risk-free rate in the longer-term are more stable than those resulting from other approaches, in line with the slow-moving character of changes in structural variables, like long run interest rate expectations. In making our modeling choices we chose to take the cyclical and long-run dynamics of the model as the key areas of focus.

The remainder of this paper is as follows: Section II discusses the main approaches to term premia estimation, explain the input data and variables, and specifies the dynamic State Space model. Section III summarizes the main results, including estimates of the term premium, the behavior of the variables, and ... Section IV concludes.

\section{MOdeling The Term Structure OF InTEReST RATES}

Although there is a wide range of modeling approaches and specifications, modern term premium models do share some common structural features:

- They are almost always Gaussian. This greatly simplifies the computation. Until rates approached the zero lower bound, this assumption had little practical impact on modeling. Today, some approaches allow for non-linearities in the yield curve's dynamics (for a representative example, see Christensen and Rudebusch, 2013).

- The yields of the underlying bonds and the risk-free rate are affine in some state variables. These state variables are sometimes entirely endogenous to the yield curve but they may also include macroeconomic and financial variables, and survey data.

- The dimension of the yield curve is reduced. This can be done through unstructured crosssectional models such as principal components analysis, maximum likelihood-based factors, or a parsimonious structured model like that of Nelson and Siegel (1987).

- These factors are then given some intertemporal structure in a vector-autoregressive (VAR) type model. The factor structure is then iterated forward, possibly with a risk premium component, which can be defined in a variety of ways, to generate yield expectations.

Term premium models are at their heart hybrids. They must explain the cross-section of yields well but they also need to make sensible temporal forecasts and have reasonable longrun properties. For the rest of this paper, the following definition of the term premium is applied: The term premium, $\operatorname{TP}_{t}(\tau)$, for a bond of maturity $\tau$ is the difference between the bond's yield, $y_{t}(\tau)$, and the expectation of the risk-free rate over the life of the bond:

$$
T P_{t}(\tau)=y_{t}(\tau)-\frac{1}{\tau} \int_{t}^{t+\tau} E_{t}^{P}\left(r f_{s}\right) d s
$$


Under this definition, the term premium is a residual between observed yields and expectations of risk-free rates. As under normal conditions expectations of future short-term rates evolve rather slowly, and term premia are the primary drivers of yield movements, particularly for longer maturity bonds (see also Crump and others, 2018).

\section{A. Data and Variables}

Like many other empirical studies, the approach presented in this paper uses the Gurkynak et al. (2006, GSW) bond yields maintained and updated by the Federal Reserve. It fits a Nelson-Siegel-Svensson curve to off-the-run United States Treasury bonds, while removing (less liquid) bonds which have been trading erratically. This specification is effective at capturing the general shape of the yield curve (including level, slope, curvature, and convexity effects), while smoothing through the noise of individual securities and the liquidity and specialness of very recently issued bonds, which can distort analysis based on smaller underlying samples of bonds. The GSW dataset also provides the parameters of the underlying Nelson-Siegel-Svensson curve for each point in time.

\section{Table 1: Destriptive Statistics of the Input Data}

\begin{tabular}{|c|c|c|c|c|c|c|c|}
\hline & Mean & St. dev & Min & Max & $A C(1)$ & $A C(12)$ & $A C(36)$ \\
\hline 3 & 4.93 & 3.31 & 0.03 & 16.49 & 0.98 & 0.84 & 0.54 \\
\hline 6 & 4.98 & 3.32 & 0.09 & 16.22 & 0.99 & 0.86 & 0.57 \\
\hline 9 & 5.05 & 3.32 & 0.08 & 16.18 & 0.99 & 0.86 & 0.60 \\
\hline 12 & 5.12 & 3.31 & 0.10 & 16.11 & 0.99 & 0.87 & 0.62 \\
\hline 15 & 5.18 & 3.29 & 0.13 & 16.02 & 0.99 & 0.88 & 0.64 \\
\hline$\stackrel{\breve{L}}{+}$ & 5.24 & 3.28 & 0.14 & 15.91 & 0.99 & 0.88 & 0.65 \\
\hline ¿ & 5.29 & 3.26 & 0.16 & 15.81 & 0.99 & 0.88 & 0.67 \\
\hline$=$ & 5.34 & 3.24 & 0.19 & 15.78 & 0.99 & 0.89 & 0.68 \\
\hline$\frac{\mathrm{E}}{\mathrm{S}}$ & 5.44 & 3.20 & 0.24 & 15.69 & 0.99 & 0.89 & 0.69 \\
\hline$\stackrel{+}{\mathbb{N}}$ & 5.53 & 3.15 & 0.31 & 15.57 & 0.99 & 0.90 & 0.71 \\
\hline$\frac{2}{0}$ & 5.68 & 3.07 & 0.45 & 15.35 & 0.99 & 0.90 & 0.73 \\
\hline 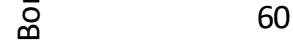 & 5.81 & 2.99 & 0.63 & 15.18 & 0.99 & 0.90 & 0.74 \\
\hline 72 & 5.93 & 2.92 & 0.81 & 15.06 & 0.99 & 0.90 & 0.74 \\
\hline 84 & 6.03 & 2.86 & 1.01 & 14.99 & 0.99 & 0.91 & 0.75 \\
\hline 96 & 6.11 & 2.81 & 1.20 & 14.94 & 0.99 & 0.90 & 0.75 \\
\hline 108 & 6.19 & 2.77 & 1.38 & 14.91 & 0.99 & 0.90 & 0.75 \\
\hline Level (120) & 6.26 & 2.73 & 1.50 & 14.89 & 0.99 & 0.90 & 0.75 \\
\hline Slope & -1.33 & 1.47 & -4.32 & 4.02 & 0.93 & 0.51 & -0.15 \\
\hline Curvature & -0.13 & 0.88 & -3.34 & 3.16 & 0.85 & 0.47 & 0.27 \\
\hline Unemployment gap & 0.50 & 1.56 & -2.44 & 4.98 & 0.99 & 0.77 & 0.22 \\
\hline Inflation & 3.31 & 2.18 & 0.95 & 10.23 & 1.00 & 0.87 & 0.66 \\
\hline
\end{tabular}

Note: Data are end of month yields at different maturities as well as the level of unemployment less the CBO NAIRU and the rate of core PCE inflation. The level, slope, and curvature terms refer to the standard Nelson-Siegel interpretations of these terms. Slope is defined as the 3-month yield minus the 10-year yield (this matches the NelsonSiegel interpretation) and the curvature is two times the 3-year yield less the 10-year and 3-month yields. Data is from June 1962 until March 2018. 
We create a sample of yields from June 1962 until March 2018 with maturities of 3, 6, 9,12, $15,18,21,24,30,36,48,60,72,84,96,108$, and 120 months, which is a common choice. For the bond yields, we use month-end data. The yields are then matched with the unemployment rate and core PCE inflation series from the previous month. The survey data on long-run inflation expectations from the Federal Reserve is observed in the month in which the survey took place. This ensures arriving at a data set with synchronous time series.

The set of macroeconomic variables includes the unemployment gap (the difference between the Congressional Budget Office's estimate of the NAIRU and the U3 unemployment rate) and the inflation gap (difference between observed core PCE inflation and a measure of longrun inflation expectations).

Table 1 documents some key facts about the yield curve which inform subsequent modeling choices. First, under any long enough time horizon, the average yield curve is upward sloping. Additionally, the front-end and belly of the yield curve are more volatile than is the long end as long-term rates are generally thought to be determined by long-term inflation expectations and the expected average level of the risk-free rate and the term premium.

\section{Table 2. Correlation between Yield Curve Factors and Macroeconomic Variables}

\begin{tabular}{rrrrrr} 
& Level & Slope & Curvature & U.gap & Inflation \\
\hline Level & 1 & 0.170 & 0.485 & 0.038 & 0.741 \\
Slope & 0.170 & 1 & -0.166 & -0.583 & 0.345 \\
Curvature & 0.485 & -0.166 & 1 & -0.123 & 0.260 \\
Unemployment gap & 0.038 & -0.583 & -0.123 & 1 & 0.029 \\
Inflation & 0.741 & 0.345 & 0.260 & 0.029 & 1 \\
\hline
\end{tabular}

Note: data are defined as in Table 1.

Shorter-maturity yields are relatively more affected by the business cycle and deviations of inflation away from its target value are less persistent than the structural variables embedded in the long-run level of yields. Looking at the level, slope, and curvature terms we can see this more clearly (Table 1). Interestingly, the auto-correlations of the slope and curvature terms are much more similar in magnitude to that of the unemployment gap than they are to those of the underlying yields. Table 2 shows that the slope of the yield curve is particularly affected by the unemployment gap, and the level of interest rates is strongly correlated with the level of inflation but not the unemployment gap. What is missing from this current specification is the deviation of inflation from long-run expectations, a topic we will turn to shortly.

The Dickey-Fuller and Phillips-Peron unit root tests indicate that both inflation and the level of the yield curve are subject to unit roots - whereas the yield curve's slope and curvature, as well as the unemployment rate, appear to be mean reverting series. This is plausible since 
the rate of inflation and nominal interest rates are widely thought of as being determined by monetary policy choices in the long-run. The other variables follow a (mean-reverting) Brownian motion. Figure 3 plots the two unit root series and the cyclical mean reverting series. While the level of yields and inflation series co-move, the spread between them is neither constant, nor does it appear to be strictly proportional to the level of inflation. The Engel-Granger stationarity test rejects the null that the difference between the two series is stationary, and the Johansen test signals that two independent unit roots are driving the series.

Figure 3. Unit Roots and Mean-Reverting Variables
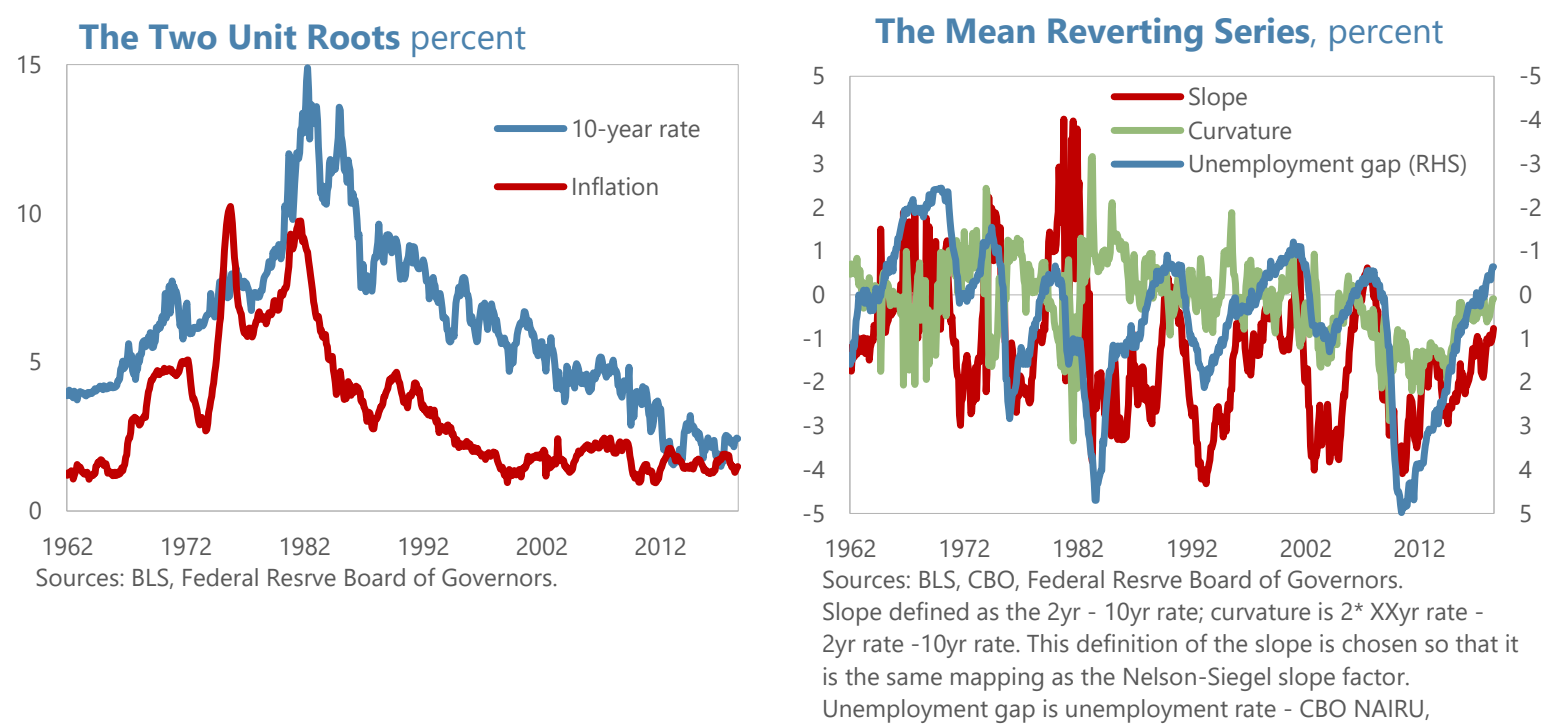

\section{B. Model Specification}

To increase robustness and yield accurate cyclical forecast, we rely on the shrinkage principal to make the model as parsimonious as possible while allowing for a realistic description of both the cross section of yields and intertemporal macro-financial dynamics. Further, we specify the dynamics in the model in a way that only under the right theoretical conditions the series can move further away from their means; in other cases, they are assumed to be simply mean-reverting. Also, modeling assumptions should be based on the statistical properties of the underlying data series. Trends and stationary series should generally be considered separate blocks of the model without cross-interactions. Finally, form macroeconomic forecasting perspective, variables are commonly modeled as gaps or deviations from long-run trends. ${ }^{2}$

The dataset covers seven fully distinct business cycles in our sample. There is broad agreement in the literature that the shape of the yield curve is likely determined by the

\footnotetext{
${ }^{2}$ Faust and Wright (2013) provide an extensive discussion of the merits of applying this approach to inflation forecasting, while Duffee (2013) makes use of similar analysis in a microfinance model.
} 
business cycle and monetary policy. But interest rates are also highly persistent. The combined issue of a small sample with highly persistent series "plagues" the estimation of any dynamic term structure model, as Christensen and Rudebusch (2012) put it. Like other approaches focused on forecast performance and macroeconomic linkages, we adopt a strategy of imposing a priori constraints based on theoretical and econometric considerations. This has been shown in Diebold and Li (2006), Christensen and Rudebusch (2012), and Duffee (2013) to be an appropriate way of improving out-of-sample forecasting power and reducing the risk of spurious correlations inside the model.

Adding macroeconomic information enriches medium-term forecasts. Given the cyclical patterns in the yield curve, ${ }^{3}$ forecasts based on most of the existing models are, effectively, factors slowly reverting to their means. While this may give an accurate representation in the very short run (which is what finance models typically focus on), it does not capture well observed macro-financial dynamics.

Our state space model is estimated using a Kalman Filter. ${ }^{4}$ While computationally intensive we believe this approach leads to a more coherent model and allows for a precise specification of the statistical properties of the series and their interactions.

The observed levels of unemployment and inflation at each time $t$ are the sum of the cyclical component, the trend, and an imposed observation error with a standard deviation of 2 basis points:

1) $U_{t}=U_{t}^{C}+N A I R U_{t}+e_{t}$

2) $\Pi_{t}=\Pi_{t}^{C}+\Pi_{t}^{*}+e_{t}$

We relax the standard assumption that the macroeconomic variables are observed without error (Bauer and Rudebusch (2016) and Joslin et al., (2013)). Even when freely estimated, our model fits the macroeconomic variables with essentially no observation error as the model is relatively parsimonious and has a number of cross equation restrictions imposed. ${ }^{5}$

\footnotetext{
${ }^{3}$ See, for instance, Bauer and Mertens (2018) and Diebold et al. (2006).

${ }^{4}$ To reduce the risk of in-sample overfitting and to ensure that the long-run dynamics of the model are plausible, the model is estimated using informative starting values for the parameters.

${ }^{5}$ However, this precision seems somewhat misleading, as bond markets are seeing data in real-time with the inherent uncertainties and data revisions that come with this. To help remedy this we take two steps to make the observed macroeconomic data more accurate. First, we lag both the unemployment and inflation rates by 1month, or one time step. Second, we impose observation error standard deviations on the unemployment and inflation rates so as to allow, in "real time", for some uncertainty in the data. Fixing the uncertainty of the macro variables at higher levels than was estimated is implicitly a form of conservatism and keeps the yields as the main parameters.
} 
The macroeconomic trends are based on the NAIRU series from the $\mathrm{CBO}$ and long-run inflation expectations from the Fed. ${ }^{6}$ Both are modeled as proxies of the true series, and are observed with errors:

1) $N A I R U_{t}=N A I R U_{t}^{C B O}+e_{t}$

2) $\Pi_{t}^{*}=\mathrm{PTR}_{t}+e_{t}$

To allow for market participants' implied views to diverge from those modeled, we allow for measurement error in the long-run levels of unemployment and inflation. We fix this error at 10 basis points for the NAIRU and 25 basis points for inflation expectations. The logic is in keeping with that of Kim and Wright (2005) and Kim and Orphanides (2012), who allow for measurement error when incorporating short horizon surveys of interest rate expectations and impose a much larger value for the survey of long-run interest rate expectations. ${ }^{7}$

Figure 4. Macroeconomic Outputs

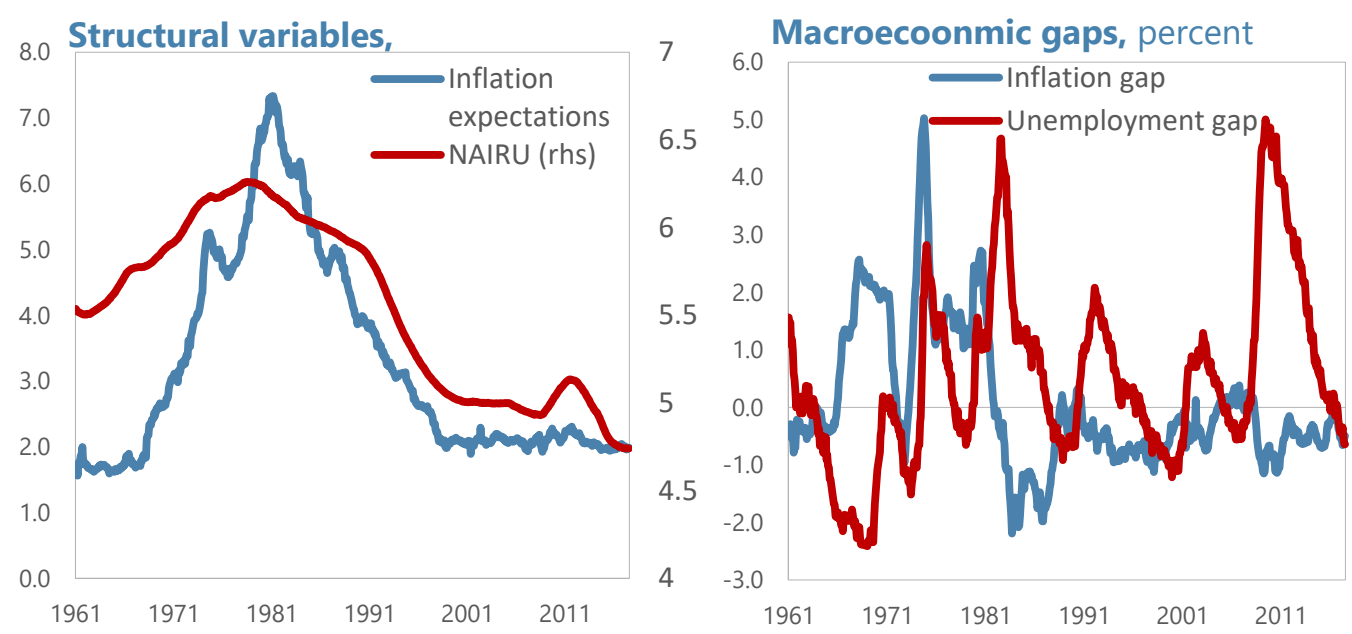

The observation equations for interest rates are based off the commonly used Nelson-Siegel specification. This ensures that the cross section of yields is accurately summarized and that the discount factors emerging from the model have desirable theoretical properties.

However, our model includes a key extension of the baseline Nelson-Siegel approach. The level term $L_{t}$ is split into two components, a long-run trend, $L^{T}$, and a cyclical component, $L^{C}$, which fluctuates around the trend. We allow the model to estimate uncorrelated i.i.d measurement errors for each of the different maturities.

\footnotetext{
${ }^{6}$ We use the PTR series from the Federal Reserve Board of Governor's staff's FRB/US model. This series is based off the Survey of Professional Forecasts long-run inflation forecast. Values prior to 1981 are estimated using a procedure similar to that in Kozicki and Tinsley (2001).

${ }^{7}$ This is because surveys or structural parameters cannot be considered data in the same way that truly observable concepts like yields, and, to a lesser extent, unemployment and prices can be.
} 
1)

$$
y_{t}(\tau)=L_{t}^{T}+L_{t}^{C}+S_{t}\left(\frac{1-\epsilon^{-\lambda \tau}}{\lambda \tau}\right)+C_{t}\left(\frac{1-\epsilon^{-\lambda \tau}}{\lambda \tau}-\epsilon^{-\lambda \tau}\right)+\epsilon_{t}
$$

The approach is borrowed from the macroeconomic forecasting literature where it is common to model series as combinations of cyclical variables fluctuating around a stochastic trend.

The model's transition dynamics are composed of two blocks. The cyclical comprises stationary series that include the cyclical component of the level of yields (our primary modeling innovation), slope, curvature ${ }^{8}$, and the cyclical components of inflation and unemployment. The trend component of the level of interest rates: the long-run level of expected inflation and the long-run level of real yield curve (i.e., the two unit root series). While the model largely incorporates macroeconomic information and uncertainty, it does not allow for the macroeconomic information to directly impact the estimation of the yield curve (i.e., the macroeconomic factors are unspanned ${ }^{9}$ by information in the yield curve). The time-varying factors for structural and cyclical factors are shown in Figures 5 and 6, respectively.

There is substantial evidence for a temporary component to the level of yields, influenced by its autocorrelation and an inflation variable, although the overall level of interest rates is a martingale. ${ }^{10}$ Cieslak and Povala (2011) find that lagged past values of inflation help explain the level of interest rates and excess returns. However, Duffee (2013) points out that lags of the term structure have explanatory power for the level of rates, suggesting that it is possible that the macroeconomic predictability is spurious. We argue that allowing for a gap to develop between the observed level of interest rates and that implied by macrostructural fundamentals alleviates this problem.

The trend level is determined by the trend level of inflation and the trend level of long-run real interest rates. Both are estimated as simple unit roots. However, we constrain their variances ${ }^{11}$ to be the same:

2) $L_{t}^{T}=\Pi_{t}^{*}+\Psi_{t}^{T}$

3) $\Pi_{t}^{*}=\Pi_{t-1}^{*}+\varepsilon_{t}$

\footnotetext{
${ }^{8} \mathrm{We}$ allow the parameter that sets where the curvature factor has its peak loading to be estimated by the Kalman Filter on the term structure data in our dataset. This gives a value of 0.0423 for our standard model, slightly below what is commonly used. Diebold and Li (2006), for instance, suggest a parameter value of 0.0609 , which maximizes the curvature exactly at three years maturity.

${ }^{9}$ See Rudebusch and Bauer (2016) and Joslin et al. (2014) for a discussion of the literature.

${ }^{10}$ Ludvigson and $\mathrm{Ng}(2009,2010)$.

${ }^{11}$ While the degree of shocks affecting these two processes are probably not the same at any point, this seems to be a reasonable assumption over the full sample.
} 
4) $\Psi_{t}^{T}=\Psi_{t-1}^{T}+\varepsilon_{t}$

Additionally, if the total variance of $L_{t}^{T}$ is not constrained then the model struggles to distinguish between these and other shocks affecting the overall level of rates. We chose to focus on the real long-run rate instead of the real short-term rate $r^{*}$ because $r^{*}$ is naturally embedded inside $\Psi_{t}^{T}$ and this allows for equilibrium risk premium to vary over time. Bauer and Rudebusch (2017) see similar overall results to ours, while focusing on the short-term policy rate and trending expectations of the fed funds rate over time. This suggests that the $\mathrm{r}^{*}$ vs long-run real rate distinction is less important than allowing for both trend real rates and inflation expectations to vary over time.

Figure 5. Trends in Interest Rates

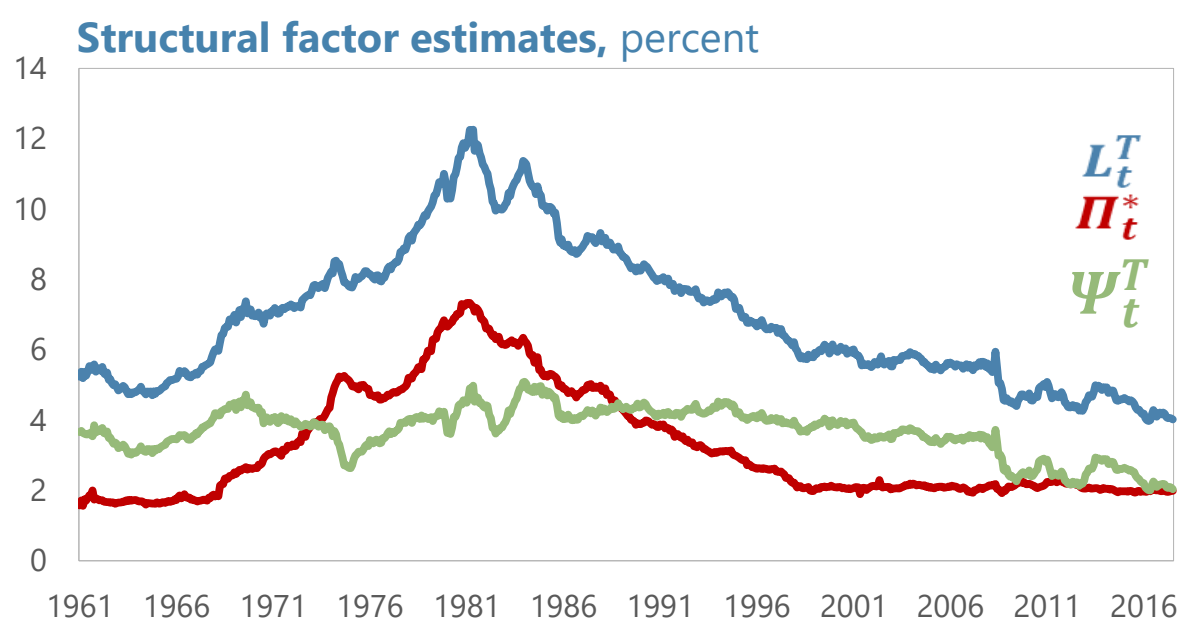

Figure 6. Cyclical components of interest rates

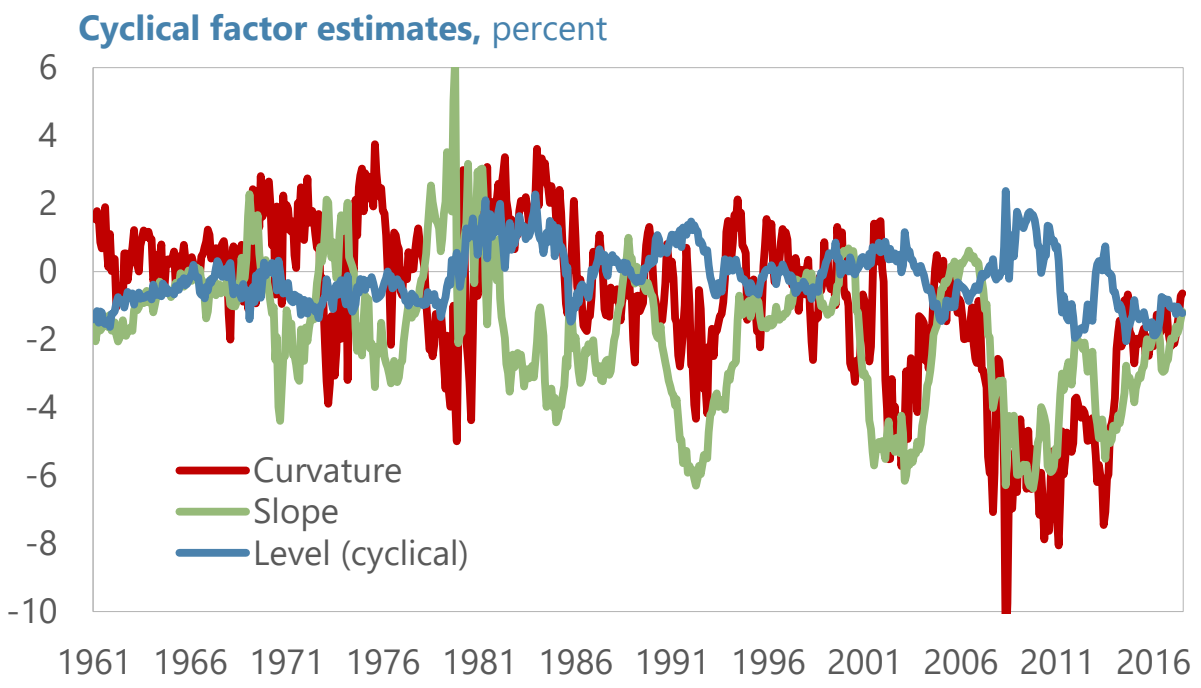


The NAIRU is also assumed to be a unit root and only affects the rest of the variables through the unemployment gap:

1) $N A I R U_{t}=N A I R U_{t-1}+\varepsilon_{t}$

Intertemporal dynamics are modeled in a VAR framework. In the transition equations, the structural variables are all modeled as combinations of unit roots. The five mean reverting series are modeled jointly in a VAR, with the assumption that the means of the $L_{t}^{C}, U_{t}^{C}, \Pi_{t}^{C}$ are zero: ${ }^{12}$

$$
\text { 2) } \begin{gathered}
\left(\begin{array}{c}
L_{t}^{C} \\
S_{t} \\
C_{t} \\
U_{t}^{C} \\
\Pi_{t}^{C}
\end{array}\right)=(I-A)\left(\begin{array}{c}
0 \\
\mu_{1} \\
\mu_{2} \\
0 \\
0
\end{array}\right)+\left(\begin{array}{ccccc}
a_{11} & 0 & 0 & 0 & 0 \\
0 & a_{22} & 0 & a_{24} & a_{25} \\
0 & 0 & a_{33} & a_{34} & a_{35} \\
a_{41} & a_{42} & a_{43} & a_{44} & a_{45} \\
a_{51} & a_{52} & a_{53} & a_{54} & a_{55}
\end{array}\right)\left(\begin{array}{c}
L_{t-1}^{C} \\
S_{t-1} \\
C_{t-1} \\
U_{t-1}^{C} \\
\Pi_{t-1}^{C}
\end{array}\right)+\epsilon_{t} \\
\epsilon_{t} \stackrel{i i d}{\sim} N\left(0, \sigma_{t}\right)
\end{gathered}
$$

For identification purposes, we assume that $L_{t}^{C}$ is solely a product of the level of observed interest rates.

Besides splitting the state dynamics into separate trend-cycle blocks, we impose an additional a priori constraint that the covariance matrix of the states is diagonal. This ensures that there are no direct interactions between the cyclical terms and the trends. It does not preclude longer-run cyclical impacts on the trend variables, however, because the data may move the trends over the course of the cycle given the evolution of the macro-financial environment, but it does not happen noisily or instantaneously. We believe this aids in identifying the underlying trend-cycle dynamics and reduces the risk of overfitting.

Figure 7 shows 10-year term premium estimates from four different methodologies. As mentioned earlier, term premia estimates can differ substantially, especially during recovery phases when long-term rates rise and term premia decompress. In the early phase of the current expansion, most approaches estimate 10-year term premia around 2 percent, and also the subsequent compression of term premia is common to most estimates. Overall, our estimate is less prone to short-lived spikes, and appears to react as expected over the different cycles.

\footnotetext{
${ }^{12}$ Empirically, $U_{t}^{C}$ and $\Pi_{t}^{C}$ are not precisely zero over our sample but imposing this constraint helps ensure that the model has reasonable long-run properties and is not a victim of small-sample bias.
} 
Figure 7. Comparison of 10-year term Premium Estimates

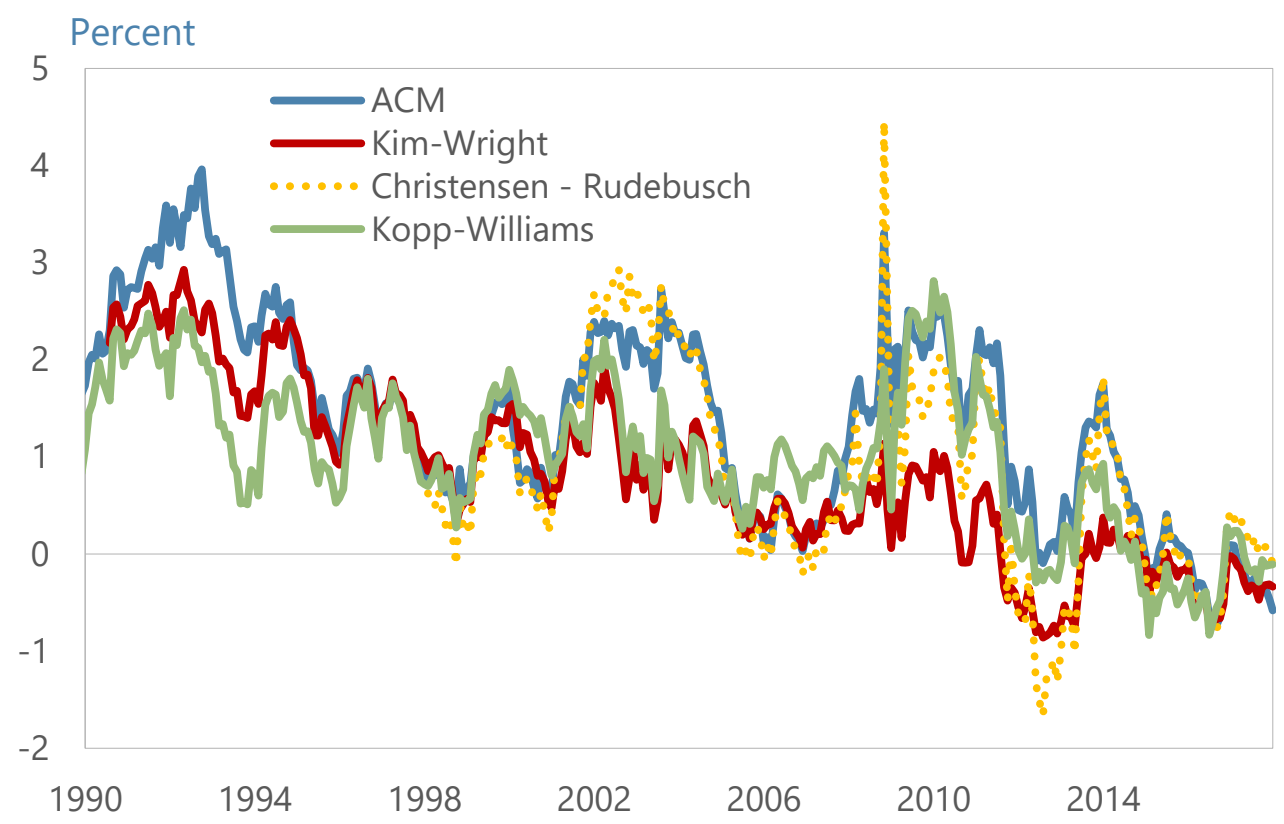

Figure 8 gives the average term premia for different maturity buckets, from 1 to 10 years. This concave shape of risk premia is a common finding. Additionally, the expected Sharpe ratios decline as maturities increase. This decreasing risk-adjusted return to maturity extension is also in line with the literature.

Figure 8. Average Term Premia

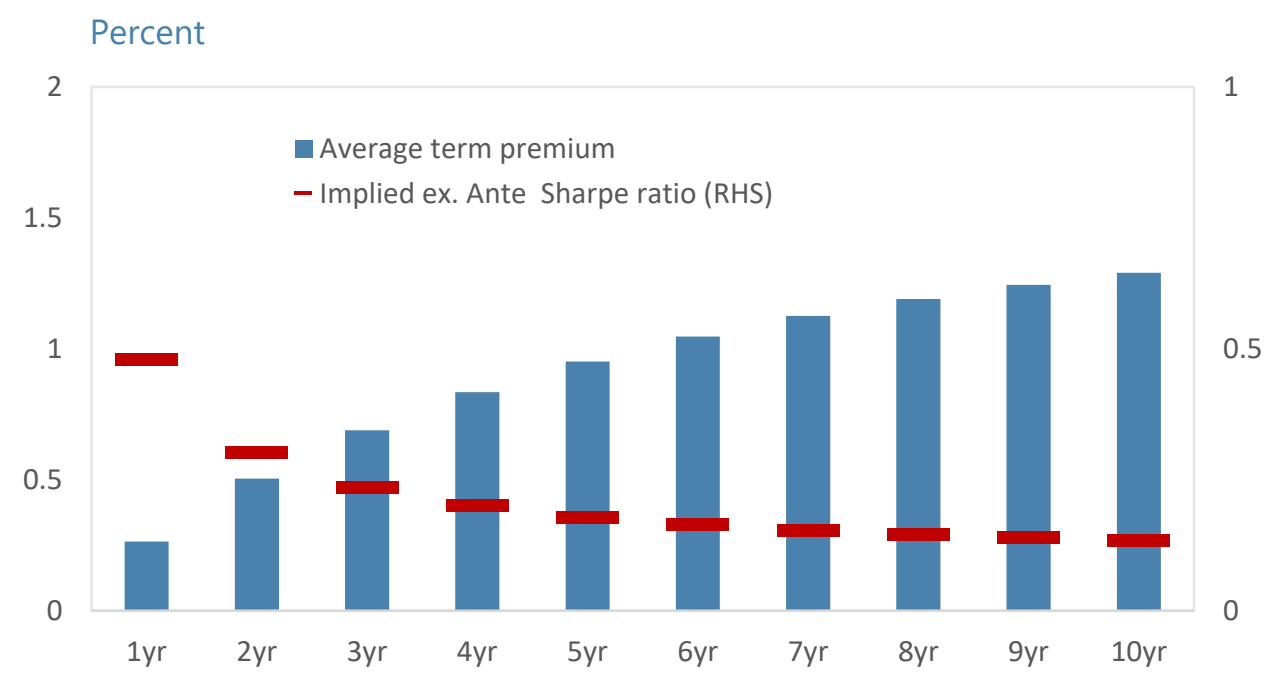

Source: IMF staff estimates. Implied Sharpe ratio calculated as avg. term premium divded by the product of the st.dev. of changes in the term premium and the given bond's duration. Based on sample from 1962 on., 


\section{MACROECONOMIC IMPLICATIONS}

While the macroeconomic literature may give some credence to the notion of possible hysteresis induced by large recessions (see Yellen, 2016, for a discussion), the recognition of this in bond markets seems to be a slower, less discrete process. The survey of professional forecasters suggests that it has taken economists a number of years following the crisis to reassess their views on what the average prevailing level of interest rates is going to be. Figure 9 shows long run interest rate forecasts (left chart) and long-run forecasts of the federal funds rate (right chart). Because the levels shown in the left panel are 10-year averages, we can infer that the survey participants view of the long-run only started to fall once the recovery was well under way and markets had had time to learn from the slow recovery of the post-crisis period. Surveys of bond market participants suggest that, like members of the FOMC, the market's views of long-run interest rates have evolved only gradually following the Crisis. Both market surveys the New York Fed conducts suggest that markets have been very slow to revise their expectations of the equilibrium fed funds rate since the Crisis, supporting our view that changes in trend interest rates should be slow partial adjustments to changing-medium term dynamics.

Figure 9. Survey-based Long Horizon Interest Rate Forecasts

Long-run interest rate forecasts, percent, average over the following 10 years

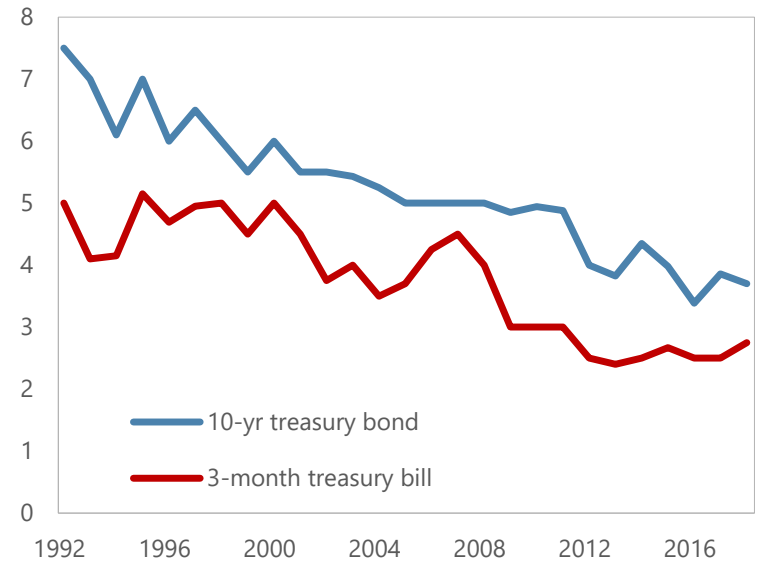

Source: Federal Resrve Bank of Philadelphia - Survey of Professional Forecasters.

Note: given the cyclical fluctuations of the 3-month Treasury bill as it closely follows the fed funds target rate, it makes sense that the average rate over the following ten years would exhibit some cyclical variation.
Forecasts of the fed funds rate over the longer-run, percent

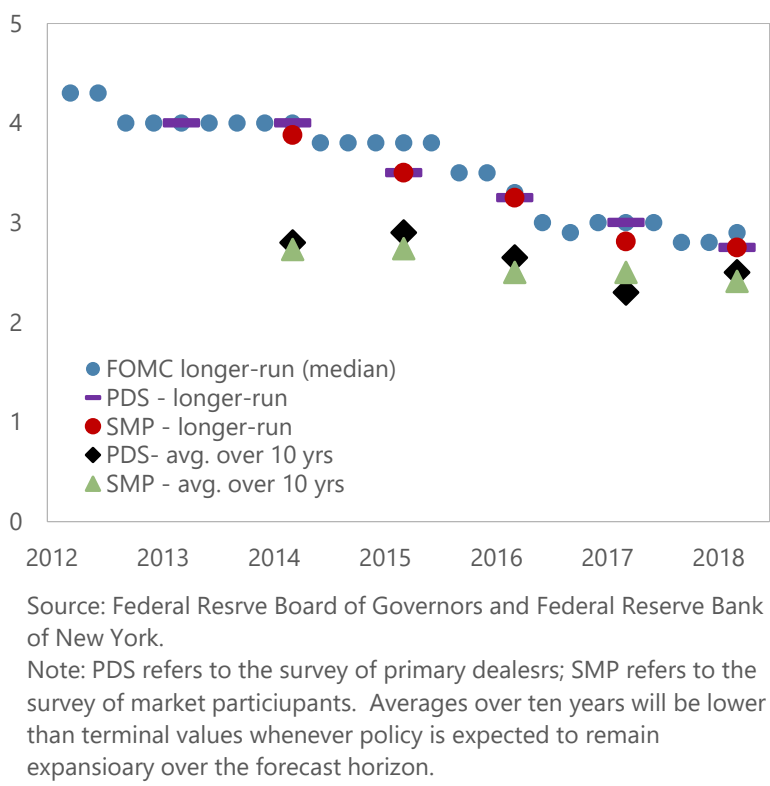

Our macroeconomically focused approach appears to be most differentiated from other models when looking at expectations of risk free rates in the longer-term (Figure 10). By 
allowing for the trend level of interest rates to vary over time, we create more stable long-run expectations of interest rates.

Figure 10. Expected Risk-Free Rates in the Longer-Term

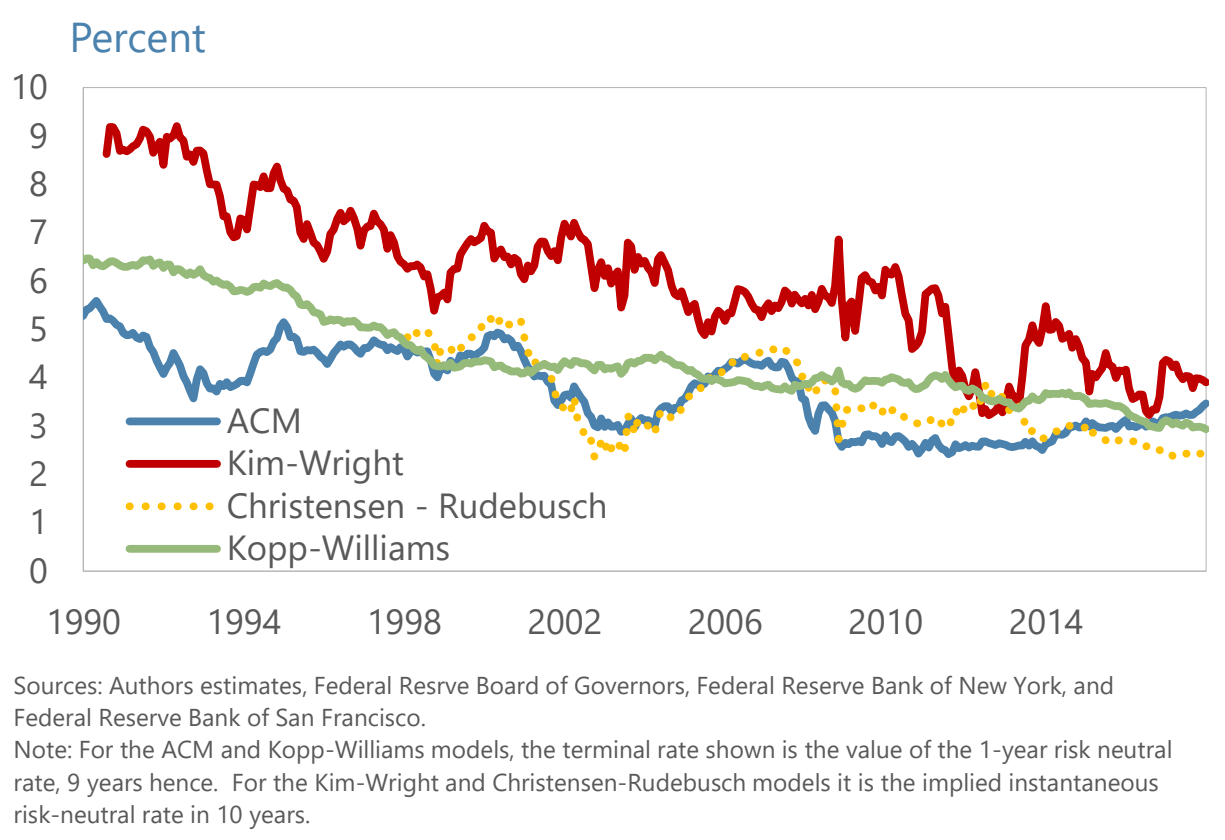

Given the different behavior of the long-run rates but the relative similarity of the estimated term premia over this sample, it naturally follows that the medium-term dynamics of the models must be very different. An analysis of the term structures of the risk-neutral yields from the other three models shows that they are almost always asymptotic from the current risk-free rate to the long-horizon forward. In contrast, our medium-term dynamics almost always show risk-free rates over-or-undershooting their long-run. This is largely driven by the presence of unemployment and inflation gaps whose magnitude and relative dynamics drive the medium run forecasts.

Projections from the model (Figure 11), conditional on information available as of end-2017, indicate a further drop in the unemployment rate to around 3.5 percent by 2020 , before starting to rise again. As regards interest rates, forecasts suggest the risk-free rate will approach 3 percent by 2021, with longer maturity yields following suit. The 10 -year rate is projected to reach 3.8 percent by $2020-2021$, in line with the IMF's WEO projections for the United States. 
Figure 11. Survey-Based Long Horizon Interest Rate Forecasts
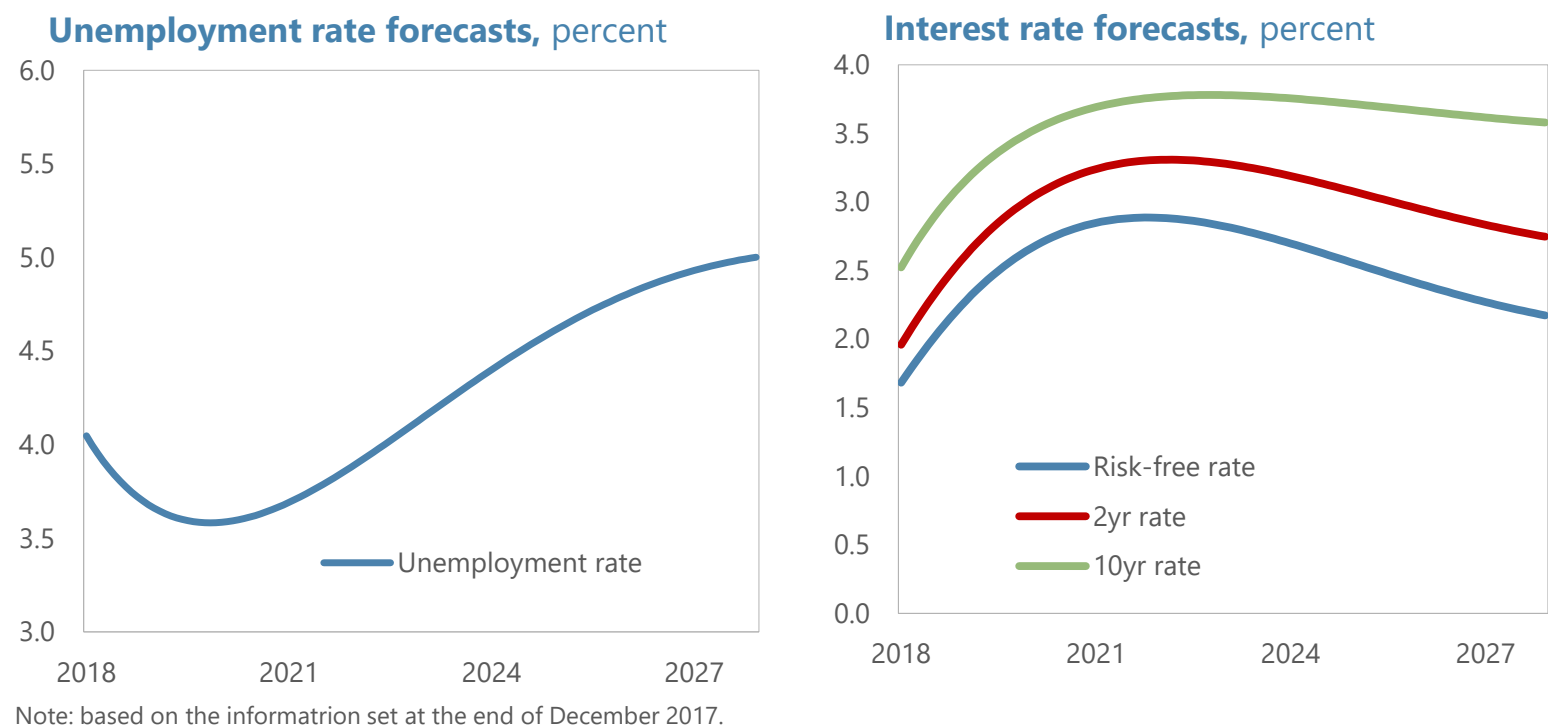

\section{CONCLUSION}

Accounting for macroeconomic trends and short-term fluctuations can be important for developing a deeper understanding of the term structure of interest rates and the information that it embeds. Expectations about structural factors like inflation or potential growth are revised only slowly, even after large shocks, pointing to high and persistent inertia in their reassessment.

In order to formalize this property, the term structure model presented in this paper exploits both the cross-sectional and temporal information embedded in the term structure of interest rates. The approach further adds cyclical dynamics that support more realistic longer-term forecasting. Estimates of the level of the risk-free rate in the longer-term are more stable than those resulting from other approaches, in line with the slow-moving nature of changes in structural variables, like long run interest rate expectations. At the same time, the short-run term premium forecasts from the model are very similar to those estimated from models that aim at high precision over the short-term.

The results show that a well specified term structure model allows generating reasonable and stable longer-term forecasts, and that a macroeconomic approach to the term premium is warranted. Estimates of the term premium resulting from the term structure models are in line with those from other studies and, at the same time, the model provides smooth and stable estimates of expected long-term interest rates, a key variable in macroeconomic forecasting and policy-making. Moreover, forecasts of short- and long-term interest rates as well as cyclical gaps in macroeconomic variables are close to those generated from largescale macroeconomic models applied by the Congressional Budget Office, the IMF, or private sector forecasters. 


\section{REFERENCES}

Adrian, Tobias, Richard K. Crump, and Emanuel Moench, "Pricing the Term Structure with Linear Regressions," Journal of Financial Economics, Vol. 110, No. 1 (October 2013): 110-38.

Bauer, Michael D., and Thomas Mertens. 2018. "Economic Forecasts with the Yield Curve" FRBSF Economic Letter 2018-07 (March 5).

Bauer, Michael D., and Glenn D. Rudebusch. 2016. "Resolving the Spanning Puzzle in Macro-Finance Term Structure Models." Federal Reserve Bank of San Francisco Working Paper 201-01.

Bauer, Michael D., and Glenn D. Rudebusch. 2017. "Interest Rates Under Falling Stars" Federal Reserve Bank of San Francisco Working Paper 2017-16.

Christensen, Jens H.E., and Glenn D. Rudebusch. 2012. "The Response of Interest Rates to UNITED STATES and U.K. Quantitative Easing.” Economic Journal, Vol. 122, pp. F385-F414.

Cieslak, A., and P. Povala. 2011. "Understanding Bond Risk Premia,” Working paper, Kellogg School of Management.

Cochrane, John. 2011. "Presidential Address: Discount Rates," The Journal of Finance, Vol. 66: $1047-1108$.

Crump, Richard., Eusepi, Stefano, and Moench, Emanuel. 2018. "The Term Structure of Expectations and Bond Yields," Federal Reserve Bank of New York Staff Reports, No. 775. May 2016; revised April 2018.

Diebold, F.X. and Li, C. 2006. "Forecasting the Term Structure of Government Bond Yields," Journal of Econometrics, 130, 337-64.

Diebold, F.X., Rudebusch, G.D. and Aruoba, B. 2006. "The Macroeconomy and the Yield Curve: A Dynamic Latent Factor Approach,” Journal of Econometrics, 131, 309-38.

Duffee, Gregory. 2002. Term Premia and Interest Rate Forecasts in Affine Models. The Journal of Finance, Vol. 57: pp. 405-43.

Duffee, Gregory. 2013. "Forecasting Interest Rates.” Chapter 7 in Handbook of Economic 
Forecasting, Vol. 2A, edited by Graham Elliott and Allan Timmermann. Amsterdam: Elsevier, pp. 385-426.

Faust, Jon and Jonathan Wright. 2013. "Forecasting Inflation" in Handbook of Economic Forecasting (G. Elliott and A. Timmermann (eds.)), Volume 2A, Elsevier.

GFSR. 2018. "IMF Global Financial Stability Report," Chapter 1. April 2018. International Monetary Fund, Washington, D.C.

Gurkaynak, Refet. 2005. "Using Federal Funds Futures Contracts for Monetary Policy Analysis," FEDS Working Paper, 2005-29.

Gürkaynak, Refet S., and Jonathan H. Wright. 2012. "Macroeconomics and the Term Structure.” Journal of Economic Literature, 50 (2): 331-67.

Joslin, Scott, Anh Le, and Kenneth J. Singleton. 2013. "Why Gaussian Macro-Finance Term Structure Models Are (Nearly) Unconstrained Factor-VARs," Journal of Financial Economics, Vol. 109, pp. 604-622.

Joslin, Scott, Marcel Priebsch, and Kenneth J. Singleton. 2014. "Risk Premiums in Dynamic Term Structure Models with Unspanned Macro Risks," Journal of Finance, Vol. 69, pp. 1197-1233.

Kozicki, Sharon \& Tinsley, P. A., 2001. "Term Structure Views of Monetary Policy under Alternative Models of Agent Expectations," Journal of Economic Dynamics and Control, Vol. 25: pp. 149-184.

Meyer, Lawrence. 2002. Rules and Discretion, At the Owen Graduate School of Management, Vanderbilt University, Nashville, Tennessee January 16. www.federalreserve.gov/boarddocs/speeches/2002/200201162/default.htm

Rudebusch, G. R., and T. Wu, 2008, "A Macro-Finance Model of the Term Structure, Monetary Policy and the Economy," The Economic Journal, Vol. 118, pp. 906-926.

Swanson, Eric T. 2006. "Have Increases in Federal Reserve Transparency Improved Private Sector Interest Rate Forecasts?" Journal of Money, Credit and Banking, Vol. 38, No. 3, pp. 791-819.

Wright, Jonathan H. 2011. "Term Premia and Inflation Uncertainty: Empirical Evidence from an International Panel Dataset." American Economic Review, Vol. 101 No. 4, pp. 1514-34. 
Yellen, Janet. 2016. Macroeconomic Research After the Crisis. at "The Elusive 'Great' Recovery: Causes and Implications for Future Business Cycle Dynamics" 60th annual economic conference sponsored by the Federal Reserve Bank of Boston, Boston, Massachusetts. www.federalreserve.gov/newsevents/speech/yellen20161014a.htm 